\title{
Cutaneous collagenous vasculopathy
}

INSERM

\section{Source}

INSERM. (1999). Orphanet: an online rare disease and orphan drug data base. Cutaneous collagenous vasculopathy. ORPHA:280779

Cutaneous collagenous vasculopathy (CCV) is a primary microangiopathy confined to the skin, characterized by multiple and widespread telang iectasias. 